\title{
Co-Simulation and Experimental Research of Wedge Broken-Belt Catching Device
}

\author{
Jun-Xia Li ${ }^{*}{ }^{, 1,2}$, Zi-Ming Kou ${ }^{1,2}$ and Jian-Wei Du ${ }^{1,2}$ \\ ${ }^{I}$ College of Mechanical Engineering, Taiyuan University of Technology, Taiyuan, 030024, China \\ ${ }^{2}$ Shanxi Province Mine Fluid Control Engineering Research Center, Taiyuan, 030024, China
}

\begin{abstract}
The paper conducted a research on a broken-belt catching machine based on full face catching. The device is a mechanical electrical hydraulic integration design, driven by hydraulic pressure to achieve catching work. This paper introduces its principle and basic composition, using ADMAS and AMESim simulation software to verify the rationality of the design. Prototype was produced for the experiment in the laboratory. The results show that the catching device can safely complete the work and the arrest meets the design requirements, without significant impact to performance.
\end{abstract}

Keywords: Broken-belt catching machine, Co-simulation, Experiment, Dynamic simulation model.

\section{INTRODUCTION}

As the best transportation equipment for transporting bulk materials, belt conveyors are now widely used in coal mines, docks and other industrial sites, particularly in the coal mining enterprises $[1,2]$. There are dozens of tons of coal transported to the ground by streaming conveyor annually, more than 60 percent of belt conveyors are inclined belt conveyor. As the main drive mechanism and bearing parts, the belt is a viscoelastic body, once the belt breaks, it will release tremendous amounts of energy in an instant, which it stored before under tension. Then the belt will drop down rapidly under its gravity and the gravity of materials it conveys, resulting in the equipment damage or casualties [3, 4]. On the basis of comprehensive analysis, this paper has designed a broken-belt catching machine, which can effectively achieve catching work to prevent accidents, while a broken-belt situation occurs.

\section{WORKS INTRODUCTION}

Broken-belt catching machine consists of four parts. The first part of the machine is hydraulic control part, which integrates all hydraulic components, including hydraulic cylinders, tanks, all kinds of manifolds, pipelines, accumulators; The second part is electrical control part, which includes the PLC processor, and all kinds of control cables; The third part is mechanical structure (the actuator of catching actions); The fourth part is signal detection part, including tachometer wheel, encoders, position sensors, strain sensors and so on $[5,6]$.

Start the capture machine, the motor [7] drive the hydraulic pump [6] delivering liquid for the system. Then the hydraulic oil flow to the hydraulic system is divided into three roads: the first road, three-position four-way directional

*Address correspondence to this author at the College of Mechanical Engineering, Taiyuan University of Technology, Taiyuan 030024, China; Tel: 13834675187; E-mail:bstljx@163.com control valve $\rightarrow$ hydraulic control one-way valve $\rightarrow$ the oil cylinder rod cavity (cylinder contraction, away from the belt); the second road, one-way valve $\rightarrow$ electro-hydraulic directional control valve $\mathrm{III} \rightarrow$ stop valve $\rightarrow$ liquid accumulator I (accumulator); the third road, check valve $\rightarrow$ Electrohydraulic directional control valve $\mathrm{III} \rightarrow$ stop valve $\rightarrow$ liquid accumulatorll(accumulator) (Fig. 1). After completion of start, the system is in holding state, the electric control system returns start signal to the belt conveyor, and the part of the signal detection gives real-time monitoring on the running state of the conveyor. If the broken-belt signal was detected, PLC will give the control instruction through a signal to cut off the power of the conveyor, then the control of electro-hydraulic directional control valve $[14,15]$ will gain electricity, and the high pressure oil will flow to the rodless hydraulic cylinder cavity quickly, which pushes the piston rod out quickly and drives mechanical part to capture broken belt.

\section{DYNAMIC SIMULATION MODEL}

The mechanical structure of the capture machine consists of frame, hydraulic cylinder, lock beam and the original fixed beam, etc. Using Solidworks to complete 3D entity modeling and simulation assembly, the assembly model is as shown in Fig. (2). In order to improve the efficiency of the operation of the joint simulation, we simplify the assembly model, removed unnecessary details and just kept the main structure, and saved as a *. $\mathrm{X}_{-} \mathrm{t}$ format. After saving the assembly model, it is loaded into the dynamics software ADAMS, as is shown in Fig. (3). Then combined with the actual working condition, the constraints, drive components and the initial conditions are added [7].

Interface is established between AMESim and ADMAS by setting the input and output variables, then open the model in AMESim and load the interface which have been generated, so that the joint simulation model is set up (Figs. 4 and 5). ADMAS dynamic model transfers power to AMESim hydraulic model, and AMESim hydraulic model 


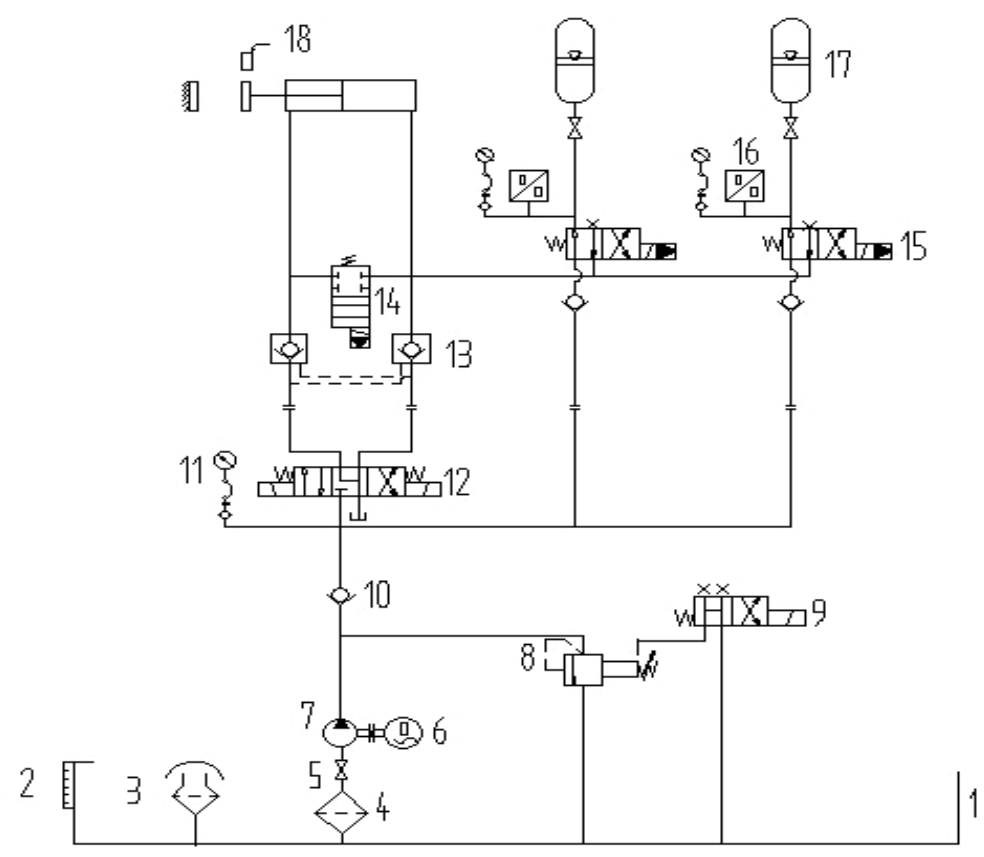

Fig. (1). Schematic diagram of hydraulic system 1-oil tank; 2-Level liquid thermometer; 3-Air filters; 4-Suction filters; 5-Shut-off valve; 6electric motor; 7-oil pump; 8-pilot relief valve; 9-solenoid valve I; 10-check valve; 11-pressure gauge; 12-three way valve; 13-pilot check valve; 14-solenoid valve II; 15-solenoid valve III; 16-pressure transmitters; 17-accumulator; 18-position sensor.

transfers displacement and velocity to ADMAS dynamic model $[8,9]$.

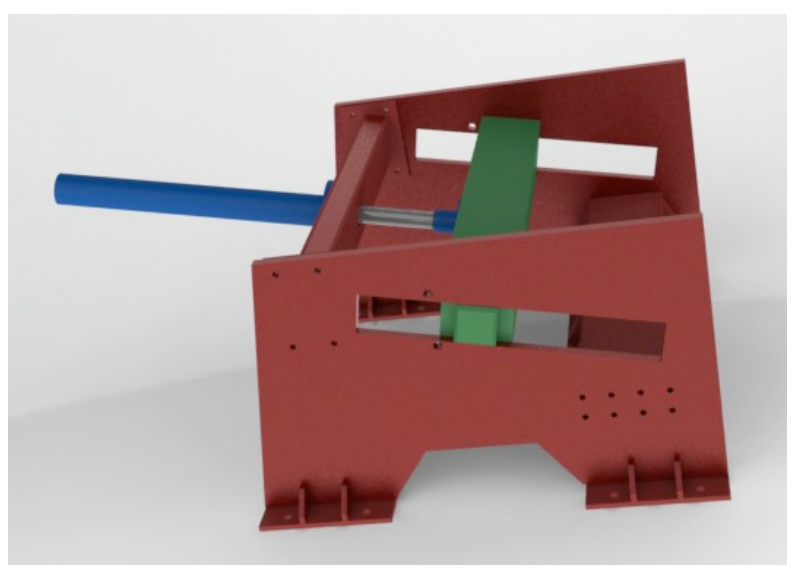

Fig. (2). 3D model.

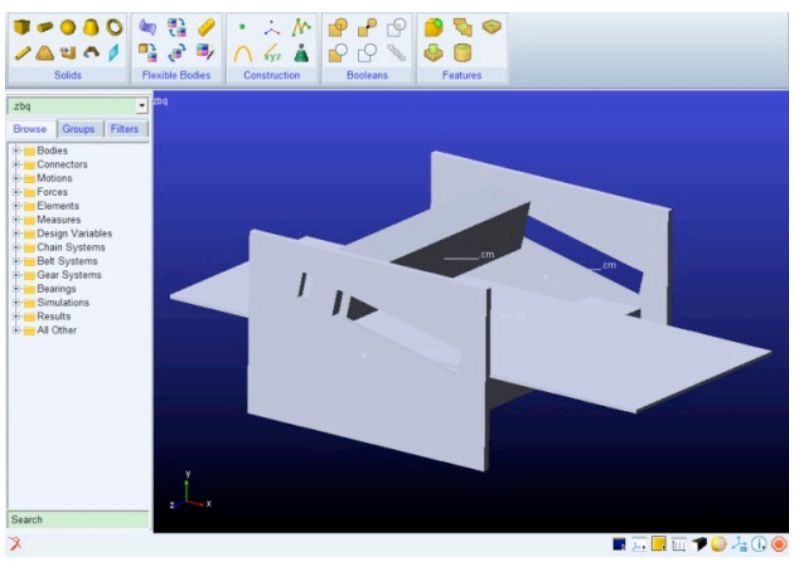

Fig. (3). ADMAS model.

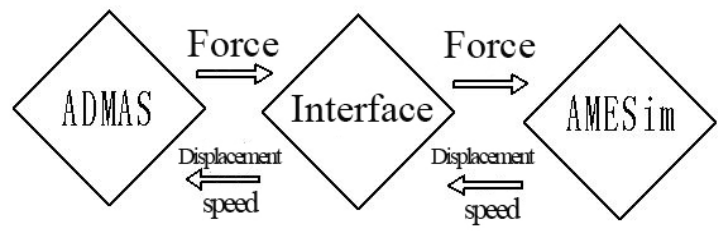

Fig. (4). Schematic diagram of co-simulation.

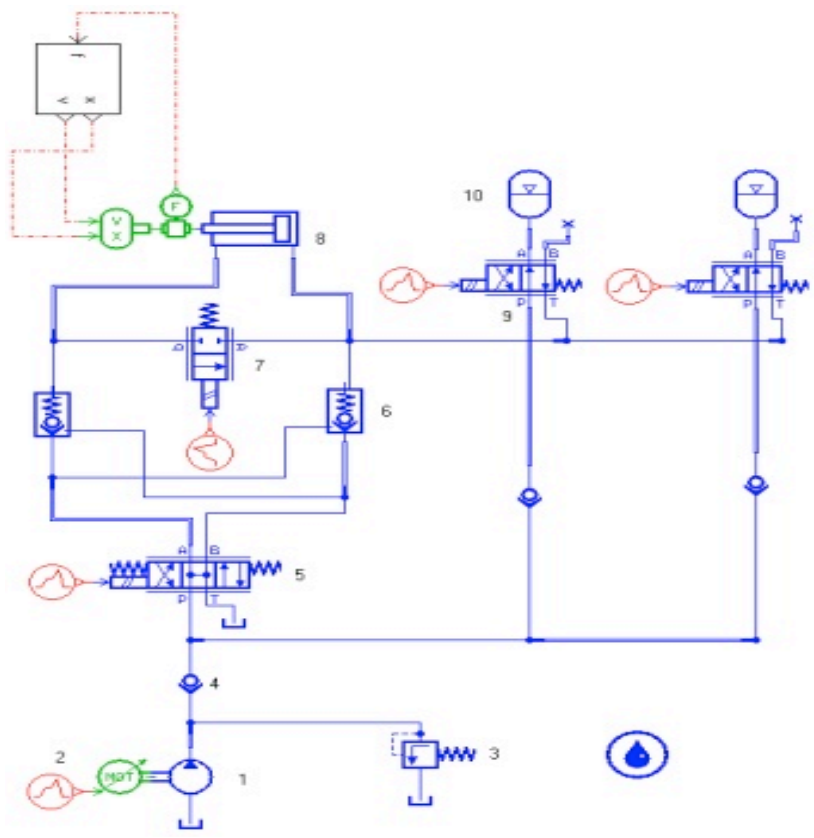

Fig. (5). Co-simulation model 1-oil pump; 2-electric motor; 3-relief valve; 4-check valve; 5-three way valve; 6-pilot check valve; 7solenoid valve II; 8-hydraulic cylinder; 9-solenoid valve III; 10accumulator. 


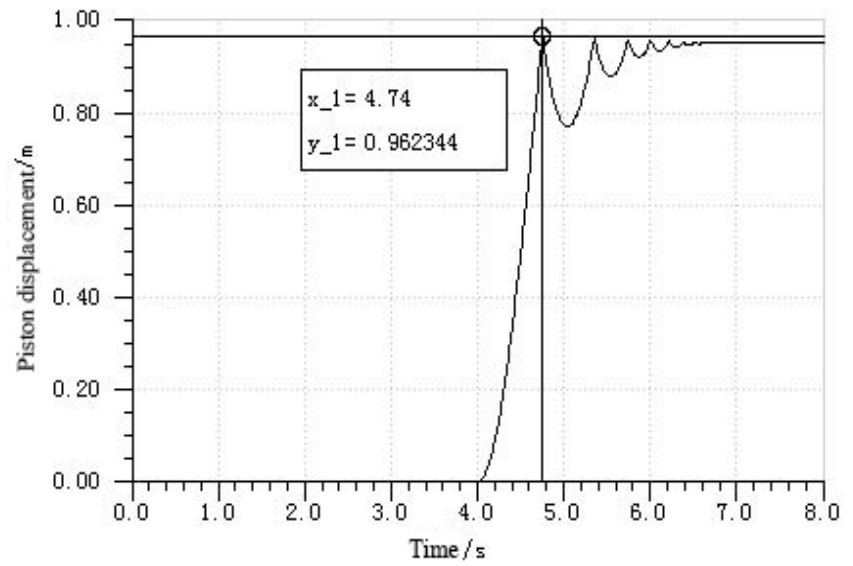

Fig. (6). Displacement curves of piston rod.

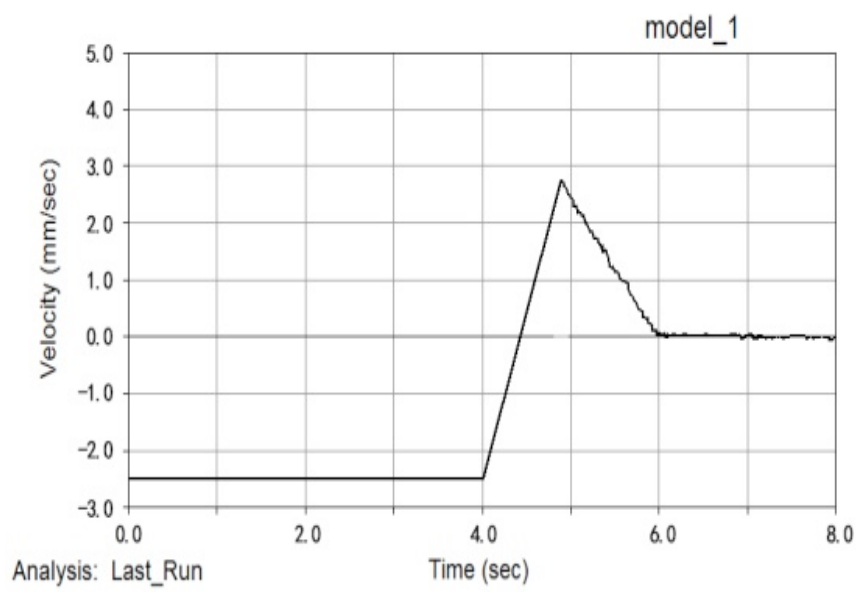

Fig. (7). Displacement of belt.

\section{CO-SIMULATION}

The hydraulic cylinder rod displacement curve over time is shown Fig. (6). The figure shows that simulate broken belt condition occurs at the time of $4 \mathrm{~s}$. At this time, the arrest triggered action by the simulation set. The rod firstly exposed to the belt at the time of $4.74 \mathrm{~s}$. So the arrest time is $0.74 \mathrm{~s}$. After several occurred rebound fluctuations, the rod tends to be stationary and arrest is completed at the time of $6.8 \mathrm{~s}$.

The graph of displacement of the belt is shown in Fig. (7). The belt running speed is set to $2.5 \mathrm{~m} / \mathrm{s}$. The broken belt condition occurred at the time of $4 \mathrm{~s}$. At this time, the belt produced the reverse acceleration through the external force. So, the speed drops to 0 firstly and then reverses rising. At the time of $4.74 \mathrm{~s}$, the reverse run of the belt meets a blockage because of the generated contact between the locking beam of catching device and conveyor. Under the role of the resistance, the speed gradually decreases to zero.

The simulation experiment illustrates that the catching device can implement stable arrest for the fracture conveyor. The test bed is built in the laboratory pilot study in order to verify the correctness of the structure.

\section{EXPERIMENTAL STUDY}

\subsection{Test System}

The test (Fig. 8) system consists of three parts: conveyor, catching device and the auxiliary tensile test device. The catching device rack and tensile testing device rack are fixed by the bolt. The one end of the belt passes through the middle of mechanical catching device and the other end passes around the shaft of the tensile test rack. The cylinder mounted on the fixed axis of the conveyor by the rope, produces tension. The electronic and hydraulic control units of catching device and the auxiliary tensile test device are properly connected by the hydraulic hoses and control cables.

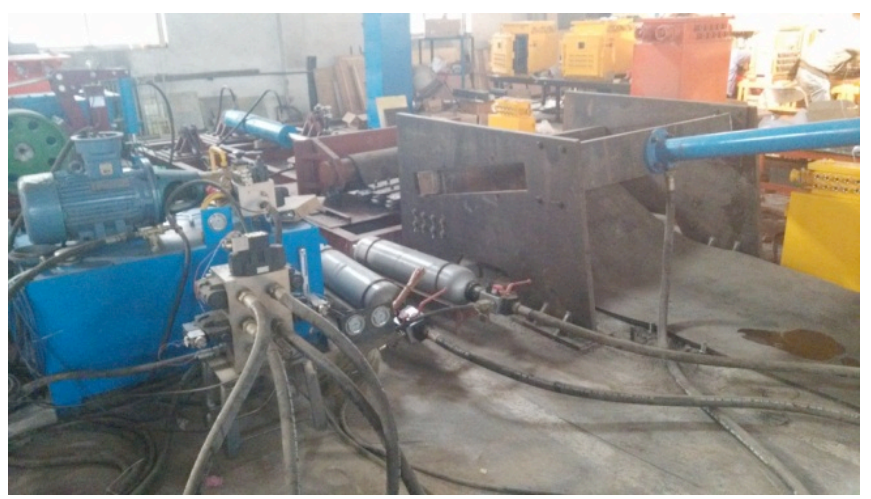

Fig. (8). Test system.

In this experiment, all kinds of the processing signals by PLC are integrated into the auxiliary tensile experiment system of the oil cylinder driven conveyor belt, so that the wheel speed is reversed, resulting in analog signal off the belt accessing through the pressure transmitter to the two groups of accumulator and hydraulic cylinders, i.e. rod cavity and rodless cavity, respectively, in order to carry on real-time monitoring of the pressure change of each point by oscilloscope data collection, and record capture device in the process of starting and catching pressure changes. In tensile testing system with tension meter in series for visual display of tension values, i.e. test results under different tension situations, the capture device can capture broken belt stably

\subsection{Start Test}

As shown in the diagram above, the curve 1 is the pressure curve of accumulator 1 , the curve 2 is for accumulator 2 , the curve 3 is for piston rod cavity, and the curve 4 is for hydraulic cylinder rodless cavity (curve meaning in below pictures are same as above). It can be seen from the diagram that curve 1 and curve 2 are basically overlapping, which shows that the change rules of two sets of accumulator are same in the process of start. System gives out a start command at $9.78 \mathrm{~s}$. At the same time, the start pumping station provides the accumulator and hydraulic cylinder rod cavity with liquid, thus the accumulator pressure rises gradually, but the piston rod doesn't move. At $8.34 \mathrm{~s}$, the pressure of accumulator and rod cavity rises synchronously, leading to the rising pressure of the rod chamber pressure rise, which at the same time brings a slight rodless cavity pressure rise. At $-7.40 \mathrm{~s}$, the rod cavity 


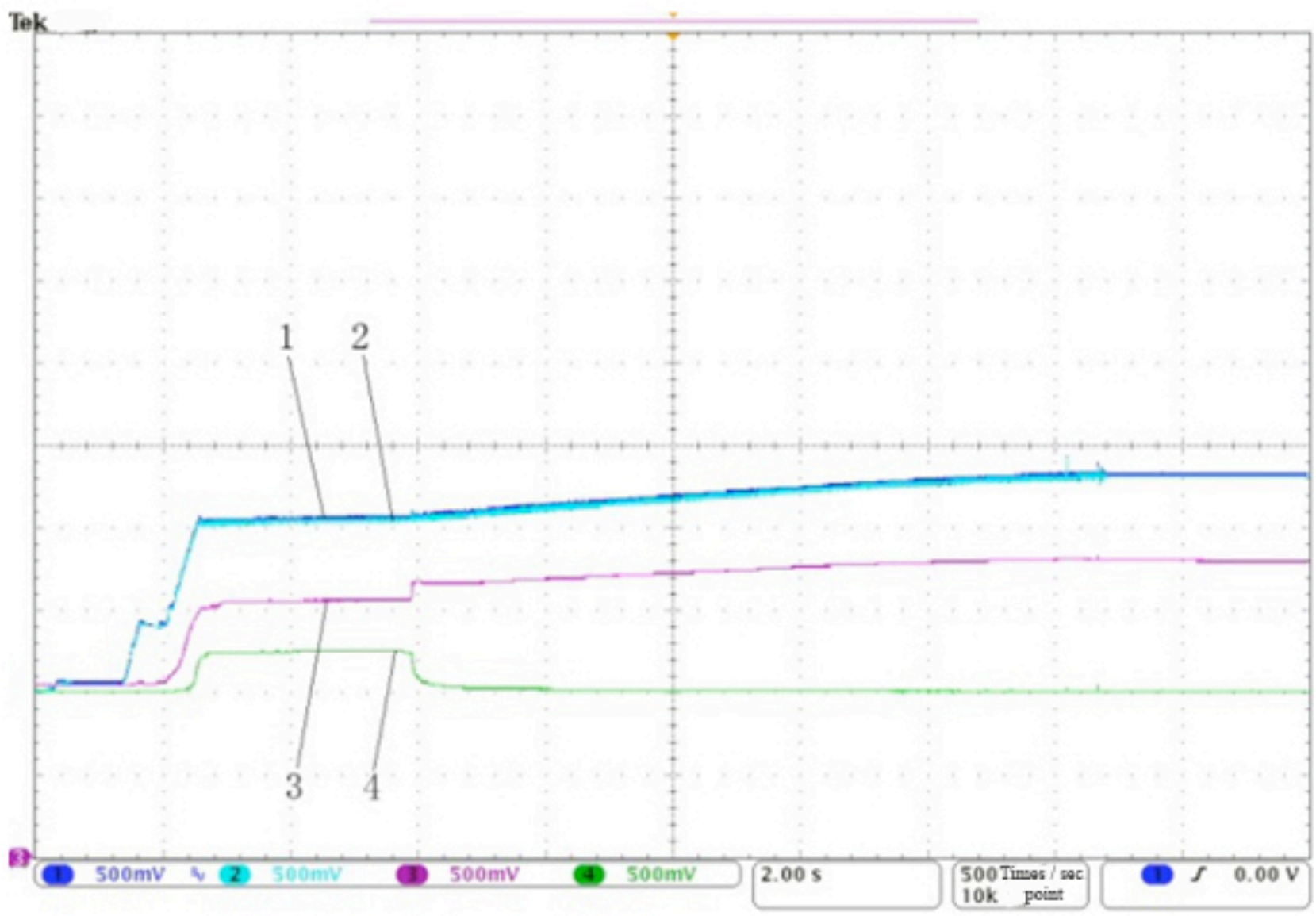

Fig. (9). Starting curves.

pressure is big enough to overcome the resistance of the piston rod, piston rod begin to shrink and the stress stays the same all around. At $-4.12 \mathrm{~s}$, the piston rod gets back to original location, the pressure of accumulator and rod cavity continues to rise at the function of oil pump, up to $6.88 \mathrm{~s}$, the system pressure reaches to the setting value, the motor stops, and the system gets into the state of keeping pressure. The process of system starts sustained 16.6s, the pressure changes smoothly and the system runs smoothly in the whole process, with no obvious fluctuation.

\subsection{Catch Test}

When at $7.1848 \mathrm{~s}$, the spinning speed-measuring device simulates broken-belt (by default the rest of three signals have occurred in this test), the two electro-hydraulic valves in front of accumulators get energized. Also, the electrohydraulic valves of the rod chamber and the rodless side chamber get energized, then the high-pressure oil in accumulator flows rapidly into the rodless side chamber of hydraulic cylinder. As can be seen in Fig. (9) clearly, accumulator I has a substantial drop at first, then it is back to a smaller peak; also accumulator II has a relatively small pressure fluctuation. This is because both accumulators I and II fill pressure in the rodless side chamber through the tubing at the same time. However, due to the constrained diameter of the tubing, the high-pressure oil from two accumulators isn't allowed to flow through it simultaneously, a phase difference between them. At 7.2322s, piston rod tends to stretch, which results in pressure oil in the rod chamber compressed, and the high-pressure oil of accumulator running blocked. So the pressure in accumulator and the rod chamber rises, and then appears peaks. After experiencing two small fluctuations, pressure in the rod chamber, the rodless side chamber and the accumulator reach a dynamic equilibrium at $7.346 \mathrm{~s}$, when the piston rod began to move, and contacted with the belt at 7.8828s (Fig. 10). The pressure in rod chamber had a small decline while the pressure in rodless side chamber had a slight increase under the effect of running resistance. The pressure had fluctuations under the effect of the high pressure oil and running resistance. The rodless side chamber pressure reaches the maximum at $7.9378 \mathrm{~s}$. Thereafter, pressure in accumulator and hydraulic cylinder gradually achieves a balance, completing the conveyor catching.

After catching, rally auxiliary experimental system and rally driving cylinder hydraulic, detecting broken-belt catching device, can test the strength and rational design of frame to make sure catch stably.

Table 1 displays values in dynamometer and calculated values in the different rally situations. As the tensile test frame is composed in a rope winding way, the tension of the belt is worth four times the dynamometer shows. Brokenbelt catching device can catch the broken-belt stably and the frame has no clear distortion when the external force is $400 \mathrm{KN}$, and thus the device has a good reliability. 


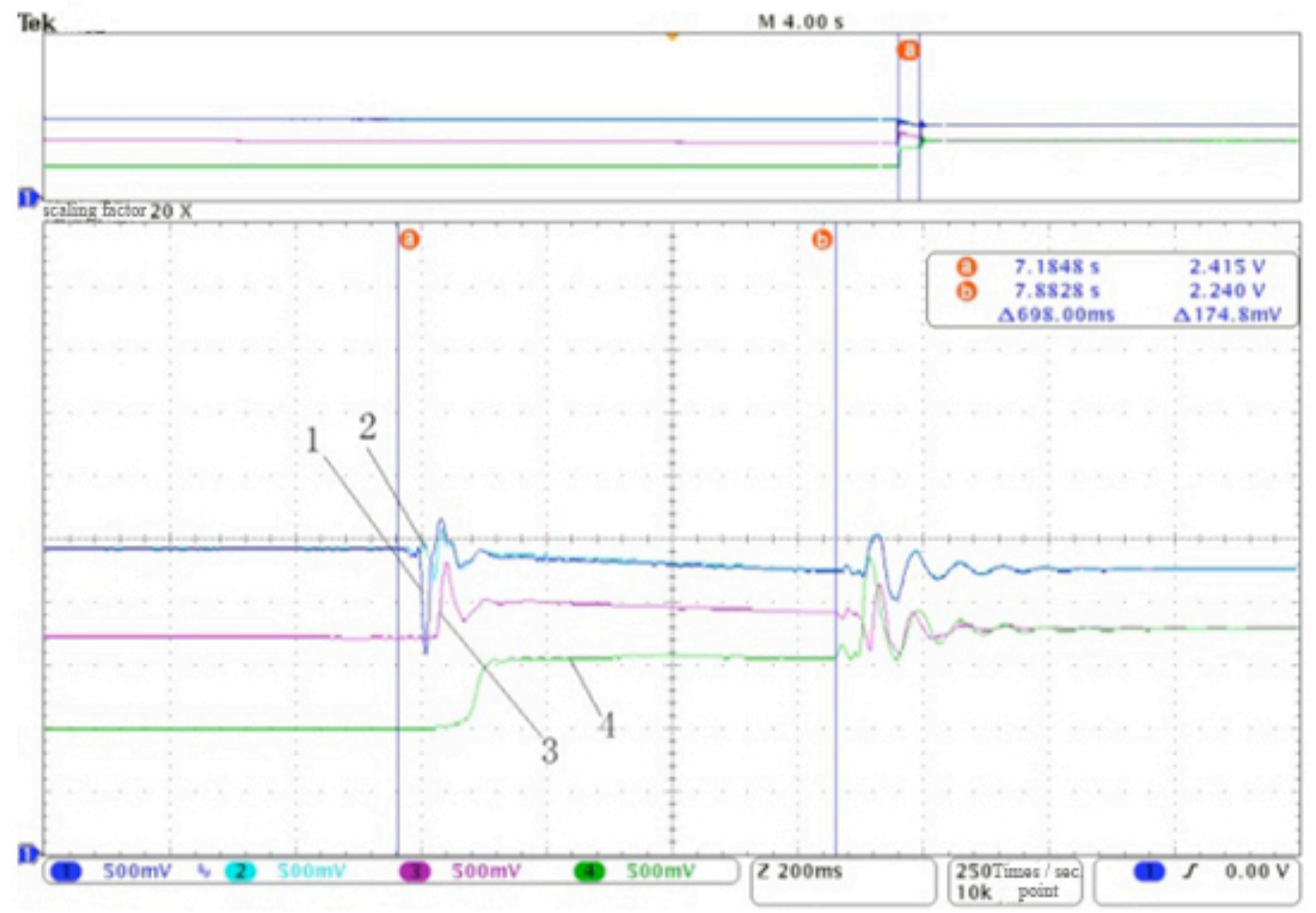

Fig. (10). Catching curves.

Table 1. Catching force experiment.

\begin{tabular}{|c|c|c|c|}
\hline System Pressure/MPa & Calculated Rally Force/t & Displayed Rally Force Value/t & Whether Self-Locking or Not \\
\hline \hline 5 & 11.78 & 5.95 & yes \\
\hline 6 & 14.13 & 7.05 & yes \\
\hline 7 & 16.49 & 8.15 & yes \\
\hline 8 & 18.84 & 9.45 & yes \\
\hline 9 & 21.20 & 10.50 & yes \\
\hline 10 & 23.36 & 11.65 & yes \\
\hline 11 & 25.91 & 12.90 & yes \\
\hline
\end{tabular}

\section{CONCLUSION}

By co-simulation, the device can catch the broken belt in $0.74 \mathrm{~s}$, meeting the design requirements. The results showed that the device started to run smoothly and without shock. Catch time is about $0.7 \mathrm{~s}$ and the device still ensures a stable catch in

\section{$400 \mathrm{KN}$ rally.}

Co-simulation and experiment all verify the rational design and reliability of the device. It can timely and reliably complete a catch. Besides, its simple structure, easy installation and maintenance, have broad application prospects in the protection of steel cord conveyor belt of high intensity.

\section{CONFLICT OF INTEREST}

The authors confirm that this article content has no conflict of interest.

\section{ACKNOWLEDGEMENTS}

The authors would like to thank for the support by National Natural Science Foundation-funded projects under the Grant 51105265 and the support by New Century Excellent Talents Support Program-funded projects under the Grant NCET-12-1038. The authors also thank for the support by Shanxi College of outstanding young academic leaders projects and the support by Shanxi Natural Science Foundation-funded projects under the Grant 2011021019-1. 


\section{REFERENCES}

[1] X. Zhang, Y. Qi, and Q. Jia, "Bilateral rotary tape off with the capture device", Coal Society, vol. 34, pp. 845-848, 2009.

[2] X. Zhu, L. Quan, and X. Wang, "The level pushed characteristic co-simulation of the large mining shovel excavator", Agricultural Machinery, vol. 42, pp. 30-34, 2011.

[3] J. Li, Z. Kou, and J. Yu, "The characteristic analysis and experimental research of hydraulic speeding soft brake for downward belt conveyor", Coal Society, vol. 38, pp. 1697-1702, 2013.

[4] J. Du, J. Li, and Z. Kou, "The simulation and experimental research of wedge broken-belt catching device", Mining Machinery, vol. 42, pp. 65-68, 2014.
[5]

[6]

J. Li, "Study on new braking system of belt conveyor", $\mathrm{Ph}$. D. thesis, Taiyuan University of Technology, Taiyuan, China. , 2014.

Q. Hou, "The simulation research based on virtual prototyping technology of broken-belt catching device", Ph. D. thesis, China University of Mining, Beijing, China, 2008

[7] Z. Zhao, and Z. Kou,"The application of downward belt conveyor brake system", Coal Science and Technology, vol. 36, pp. 64-66, 2008.

[8] Q. Tian, and W. Song, "Braking methods for belt conveyor", Material Handling and Separation Technology, vol. 36, pp. 23-25, 1993.

[9] Y. Lu, and D. Hu, "Electro-hydraulic proportional control technology", China Machine Press: Beijing, 1988.

Received: July 25, 2014

Revised: August 4, 2014

Accepted: August 4, 2014

(C) Li et al.; Licensee Bentham Open

This is an open access article licensed under the terms of the Creative Commons Attribution Non-Commercial License (http://creativecommons.org/licenses/ by-nc/4.0/) which permits unrestricted, non-commercial use, distribution and reproduction in any medium, provided the work is properly cited. 